\title{
Quality of life after septorhinoplasty measured with the Functional Rhinoplasty Outcome Inventory 17 (FROI-17)*
}

Olcay Cem Bulut, Frank Wallner, Peter K. Plinkert, Sebastian Prochnow, Christoph Kuhnt, Ingo Baumann

Department of Otolaryngology, University of Heidelberg, Germany
Rhinology 53: 54-58, 2015

DOI:10.4193/Rhino14.008

*Received for publication:

January 26, 2014

Accepted: September 21, 2014

\begin{abstract}
Background: Quality of life measurements in septorhinoplasty patients so far have taken place only to a small extent. The aim of the present study was a prospective measurement of disease-specific quality of life with a newly developed and validated instrument, the Functional Rhinoplasty Outcome Inventory 17 (FROI-17).
\end{abstract}

Methods: The patients completed the FROI-17 and the Rhinoplasty Outcome Evaluation (ROE) as disease-specific instruments preoperatively as well as 12 months postoperatively. As a general instrument, the Short Form 36 Health Survey (SF-36) was used. Furthermore, additional general questions were answered at both time points.

Results: Out of the 103 patients, 69 patients (32 men, 37 women) responded after 12 months (response rate 67\%). Thirteen patients (18\%) were not satisfied with the result of surgery. However, all scales of FROI-17 and also ROE showed a significant postoperative improvement of subjective assessments by the patients. In the SF-36, this was true in 2 out of 8 scales (mental health and role-functioning physical). Furthermore, we found significant correlations between the FROI-17 and the SF- 36 scales but not between the ROE and the SF-36 scales.

Conclusion: The disease-specific quality of life was significantly improved by septorhinoplasty. FROI-17 scales detect more functional aspects compared with the ROE thus establishing significant correlations with general quality of life measured by SF- 36 . The application of both FROI-17 and ROE in future clinical trials in septorhinoplasty patients is recommended.

Key words: FROI-17, septorhinoplasty, quality of life, SF-36, ROE

\section{Introduction}

Quality of life measurements have a growing importance in all areas of clinical medicine. In clinical rhinology, particularly in chronic rhinosinusitis, quality of life aspects have been investigated with numerous instruments ${ }^{(1)}$. Only in recent years, the quality of life aspects of septorhinoplasty were discussed. For more than 10 years the only available validated disease-specific instrument was the Rhinoplasty Outcome Evaluation (ROE) (2). This instrument focuses on the aesthetic aspects of septorhinoplasty. To evaluate both functional and aesthetic aspects of septorhinoplasty, our research group developed and validated the Functional Rhinoplasty Outcome Inventory 17 (FROI-17) ${ }^{(3)}$.
The present study was conducted with the aim to describe prospectively the change in disease-specific and general quality of life ratings by septorhinoplasty patients and to evaluate the relationships between disease-specific and general quality of life.

\section{Patients and Methods}

The Ethics Committee of the Medical Faculty at the University of Heidelberg granted permission to conduct the study (Project No. 409/2006).

\section{Patients}

One hundred and three patients (52 male and 51 female pa- 
tients) were enrolled in the study. They were $28.7 \pm 11.4$ years old. The patients were asked to fill out the questionnaires at the time of preparing for septorhinoplasty, usually the day before surgery. The second measurement was performed during an outpatient examination 12 months postoperatively. All the patients underwent primary septorhinoplasty and were operated by two of the authors (F.W. and I.B.).

\section{Questionnaires}

All the patients completed the Functional Rhinoplasty Outcome Inventory 17 (FROI-17) and the Rhinoplasty Outcome Evaluation (ROE) as disease-specific instruments preoperatively, as well as 12 months postoperatively. As a general instrument, the Short Form 36 Health Survey (SF-36) was used.

\section{General questions}

Patients were asked preoperatively and postoperatively for a general impairment of their quality of life through the nasal problem, and asked for the impairment by nasal appearance and nasal function (response options: $0=$ no impairment, 1 = very mild impairment, $2=$ mild impairment, $3=$ moderate impairment, 4 = severe impairment, 5 = extreme impairment). Furthermore, the survey was carried out postoperatively asking for satisfaction or disappointment with the result of the operation, change in symptoms after surgery and recommendation of surgery to friends or relatives with similar complaints.

\section{Functional Rhinoplasty Outcome Inventory (FROI-17)}

The FROI-17 was developed and validated by our research group (3). It consists of 17 items, with response options ranging from 0 (no problem) to 5 (as bad as it can be).

In addition to the overall score (OS) (items 1 to 16), subscores were introduced. The subscore "Nasal symptoms" (NS) includes the following items "Nasal obstruction", "Constantly running nose", "Secretions flow into the throat", "Thick mucous nasal discharge", "Dry throat", "Feeling of pressure on the ears" and "OIfactory impairment". The subscore "General symptoms" (GS) contains the items "Trouble falling asleep", "Nocturnal awakening", "Daytime sleepiness", "Poor concentration", "Decreased energy", "Irritability" and "Depression" and the subscore "Self-confidence" (SC) asks for "Low self-esteem" and "I'm embarrassed by the shape of my nose". The additional 17th item is a global issue to assess the overall effect of the nose on quality of life. The OS and the subscores were transformed to a 0-100 scale by dividing the sum of the raw scores of the items by the sum of spans of the items followed by multiplying by 100 .

\section{Rhinoplasty Outcome Evaluation (ROE)}

The ROE was developed and validated by Alsarraf et al. (2). It contains six items each with five response options graded from zero to four. Therefore, the score of the questionnaire may vary from zero to 24. To transfer the score into a 0-100-scale, the calculated score has to be divided by 24 and multiplied by 100 . Higher scores indicate greater satisfaction of the patient with his nose. Five out of six items are related to aesthetic aspects and one item is related to the breathing function of the nose.

\section{Short Form 36 health Survey (SF-36)}

The SF-36 Health Survey consists of 36 items organized into several subject areas ${ }^{(4)}$. Each item represents a scale in itself or part of a scale. The SF-36 Health Survey records eight aspects of subjective health using different item numbers (physical functioning $[\mathrm{PF}]$, role-functioning physical [RP], bodily pain [BP], general health [GH], vitality [VT], social functioning [SF], role-functioning emotional [RE], and mental health [MH]).

Rules for item scoring and scales are available in the SF-36 Scoring Manual. The German translation and the validation of the German translation were carried out by Bullinger and Kirchberger ${ }^{(5)}$. Evaluation occurs by summation of the ticked item responses per scale, whilst assigning higher weighting to some scales. The scales could then be evaluated when fewer than 50 $\%$ of the items were missing. In such a case the mean values of the existing items of a scale were used to substitute the missing items. All scales were transformed to values between 0 and 100 to allow comparisons of scales with one another and between various patient groups. Higher scores indicate a more positive rating.

\section{Statistics}

Statistical analysis was performed using the statistical software JMP ${ }^{\oplus}$ version 9.0.0 (SAS Institute Inc., Cary, NC, USA). Testing for significant differences between two groups of patients was performed using the t-test for two independent samples. Testing for differences between two expected values of a group of patients over time was performed using the t-test for two related samples. For the measurement of correlation between two samples, the Pearson correlation coefficient was used. Determining if the rear nonrandom associations between two categorical variablesexists, Fisher's exact test was used. The significance level was set at $\mathrm{p}<0.05$.

\section{Results}

Out of the 103 patients 69 patients ( 32 men, 37 women) responded after 12 months (response rate 67\%). The data from these patients were used for further evaluation. A bias between the responding and non-responding patients with respect to age ( $p$ $=0.87, t$ test $)$ and gender ( $p=0.4$, Fisher's exact test) could be excluded.

Preoperatively, 46 patients (67\%) reported that improvement of form and function of the nose were equally important, while 18 patients (26\%) were focused exclusively on the function of the nose and 5 patients (7\%) were only interested in an improve- 


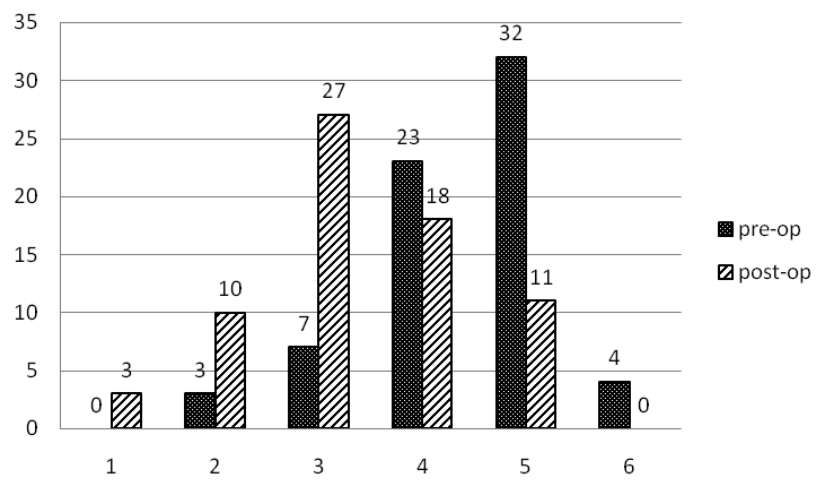

Figure 1. Number of patients impaired by nasal function.

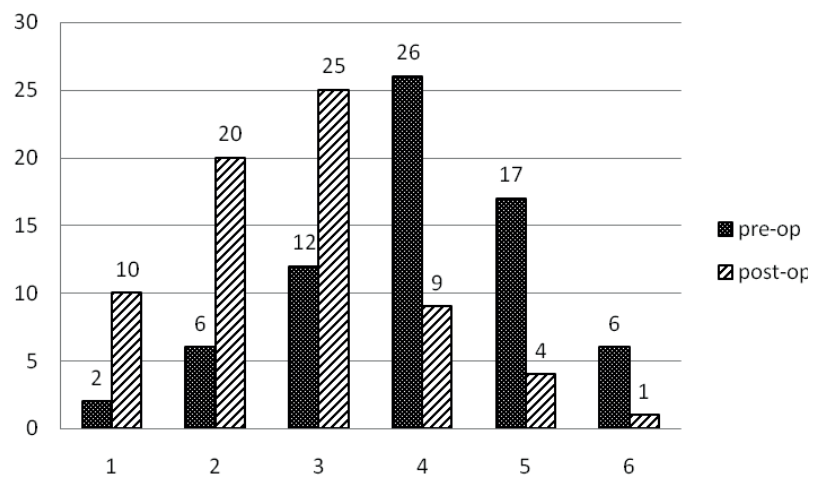

Figure 2. Number of patients impaired by nasal appearance. ment of nasal appearance. The functional and aesthetic impairment of the nose was reduced significantly after surgery (Figure 1 and 2, p $<0.0001$ for both aspects in chi² tests).

Forty-three patients (63\%) were completely or mostly satisfied with the result of surgery and 13 (18\%) were not while another 13 patients were undecided regarding this question. Fortyseven patients (68\%) would recommend septorhinoplasty to friends or relatives and $6(9 \%)$ would not while $16(23 \%)$ were undecided.

All scales of FROI-17 and also ROE showed a significant postoperative improvement of subjective assessments by the patients. In the SF-36, this was the case in 2 scales (role-functioning physical and mental health) (Table 1).

In the correlation analysis of the SF-36 versus the two diseasespecific instruments $\mathrm{FROI}-17$ and ROE significant correlations were only found between SF-36 and FROI-17 but not between SF-36 and ROE (Table 2, preoperative analysis). Postoperatively, correlations between SF-36 and FROI-17 were also significant but turned out somewhat weaker. There was no significant outcome difference regarding gender distribution.

\section{Discussion}

Subjective evaluation of results with special regard to the patient's satisfaction is a daily challenge in rhinoplasty patients (2). Three substantial aspects of the outcome of rhinoplasty have been highlighted in the literature: quantitative measurement of nasal appearance changes, quantitative and qualitative changes of nasal function, and subjective assessment of patient satisfaction and health-related $\mathrm{QOL}{ }^{(6)}$

This work deals with subjective assessment of patient satisfaction and health-related QOL. The FROI-17 is a newly developed disease-specific instrument ${ }^{(1)}$. In this paper, we report the first results of this questionnaire. The only previously available disease-specific instrument, the ROE, covers aesthetic aspects in 5 out of 6 questions and depicts functional aspects in one question (2).

Long-term results of revision rhinoplasty were collected retro- spectively with this instrument and showed that $72-88 \%$ of the patients were satisfied with the result of the operation ${ }^{(7,8)}$. In a prospective study, significant improvements in ROE scores were reported ${ }^{(9)}$. Age, sex and revision surgery in this study had no

Table 1. Preoperative versus postoperative testing (t-test) of the FROI-17, ROE and SF-36 scales.

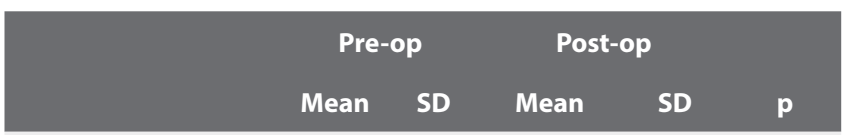

FROI-17

\begin{tabular}{|lccccc|}
\hline Overall score & 32.5 & 18.2 & 20.3 & 18.4 & 0.0001 \\
\hline Nasal symptoms & 32.4 & 16.1 & 20.9 & 19.3 & 0.0002 \\
\hline General symptoms & 32.8 & 24.8 & 20.6 & 21.5 & 0.003 \\
\hline Selfconfidence & 32.2 & 27.5 & 17.1 & 21.8 & 0.0005
\end{tabular}

ROE

$\begin{array}{llllll}\text { ROE overall score } & 42.2 & 15.7 & 63.9 & 18.9 & 0.0001\end{array}$

SF-36

\begin{tabular}{|c|c|c|c|c|c|}
\hline Physical functioning & 85.2 & 19.3 & 91.0 & 17.0 & 0.06 \\
\hline $\begin{array}{l}\text { Role-functioning } \\
\text { physical }\end{array}$ & 75.4 & 35.5 & 90.9 & 22.3 & 0.003 \\
\hline Bodily pain & 78.4 & 28.7 & 85.9 & 21.5 & 0.09 \\
\hline General health & 67.2 & 22.5 & 70.1 & 20.1 & 0.4 \\
\hline Vitality & 52.8 & 20.5 & 57.0 & 18.4 & 0.2 \\
\hline Social functioning & 76.3 & 25.6 & 79.2 & 23.6 & 0.5 \\
\hline $\begin{array}{l}\text { Role-functioning } \\
\text { emotional }\end{array}$ & 81.4 & 31.7 & 85.5 & 30.5 & 0.4 \\
\hline Mental health & 62.6 & 19.9 & 69.2 & 17.7 & 0.04 \\
\hline
\end{tabular}




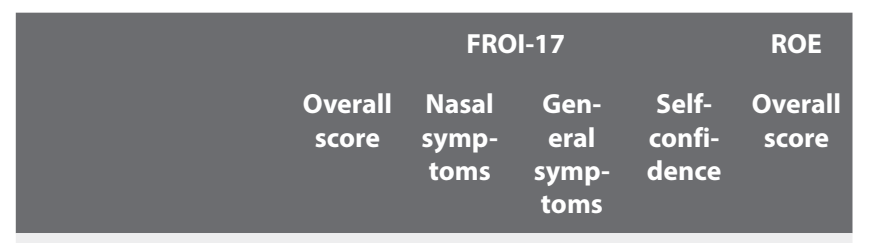

\begin{tabular}{|c|c|c|c|c|c|}
\hline Physical functioning & -0.56 & -0.51 & -0.49 & -0.37 & 0.06 \\
\hline $\begin{array}{l}\text { Role-functioning } \\
\text { physical }\end{array}$ & -0.52 & -0.42 & -0.53 & -0.23 & 0.1 \\
\hline Bodily pain & -0.63 & -0.49 & -0.62 & -0.36 & 0.04 \\
\hline General health & -0.63 & -0.62 & -0.54 & -0.37 & 0.14 \\
\hline Vitality & -0.54 & -0.37 & -0.55 & -0.33 & 0.21 \\
\hline Social functioning & -0.63 & -0.51 & -0.55 & -0.52 & 0.30 \\
\hline $\begin{array}{l}\text { Role-functioning } \\
\text { emotional }\end{array}$ & -0.45 & -0.41 & -0.39 & -0.33 & 0.06 \\
\hline Mental health & -0.55 & -0.40 & -0.53 & -0.41 & 0.21 \\
\hline
\end{tabular}

Table 2. Preoperative correlation analysis of the SF-36 scores versus FROI-17 and ROE scores using Pearson's correlation coefficient.

effect on the ROE score. In another study, an influence of osteotomies, open or closed approach and revision surgery was not detectable ${ }^{(10)}$. Patients with body dysmorphic disorder (BDD) benefited less from rhinoplasty depending on the severity of BDD symptoms ${ }^{(11)}$. Hens et al. ${ }^{(12)}$ found that the postoperative satisfaction of cleft lip and non-cleft lip patients after secondary rhinoplasty was comparable.

In our patients, we found postoperative improvements of subjective assessments of the form and function of the nose (Figures 1 and 2). However, only few patients were completely satisfied with the result of surgery. This is consistent with our clinical experience in follow-up of patients.

The subjective limitations of the patients can hardly be checked with objective measurements. Currently it was reported that after primary cosmetic rhinoplasty the subjective dissatisfaction rate was $15 \%$ and the reoperation rate was at approximately $10 \%{ }^{(13)}$. The dissatisfaction rate of $18 \%$ in our patients was comparable with the reported results from the literature. However, the operation and the postoperative course do not seem to be very unpleasant as $68 \%$ of the patients would recommend the operation to friends and relatives.

All scales of FROI-17 and ROE indicated a significant postoperative improvement. This result supports the perception that septorhinoplasty was beneficial for the patients.

In our study significant postoperative improvements in the SF-36 were detected in the scales Mental Health (sadness, happiness, exhaustion, depression, serenity) and Role-functioning physical (questions on the physical performance). The positive effect of septorhinoplasty on the scale of Mental Health of the SF-36 has already been shown in the study of Klassen et al. ${ }^{(14)}$. To understand the results of the present study with predominantly young and physically healthy patients, it is conceivable that the mental impairments of patients affected their physical conditions. The correlation analysis showed that the correlations between the scales of the SF-36 and the FROI-17 were significantly more pronounced than the correlations between the SF-36 and the ROE (Table 2). We attribute this to the fact that the FROI-17 highlights more the functional aspects of septorhinoplasty while the ROE is more focused on aesthetic aspects. Both the FROI-17 and ROE are beneficial in septorhinoplasty patients and can even adjacently be used in studies on the disease-specific health-related quality of life.

\section{Acknowledgement}

This study was supported by the European Rhinologic Society (RhiPla Grant 2010)

\section{Authorship contribution}

OCB: Designed study, collected and interpreted data, wrote manuscript and acted as corresponding author. FW, PKP: Supervised development of work, helped in data interpretation and manuscript evaluation. SP, CK: helped in collecting and interpreting data. IB: Designed study, completed statistics, wrote manuscript, helped to evaluate and edit the manuscript. Supervised development of work, data interpretation and manuscript evaluation.

\section{Conflicts of Interest}

No conflicts of interest exists

\section{References}

1. Baumann I. Validierte LebensqualitätsMessinstrumente zur Anwendung be Patienten mit chronischer Rhinosinusitis. HNO 2009; 57: 873-881.

2. Alsarraf R, Larrabee WF Jr, Anderson S, Murakami CS, Johnson CM Jr. Measuring cosmetic facial plastic surgery outcomes: a pilot study. Arch Facial Plast Surg. 2001; 3 : 198-201

3. Bulut OC, Wallner F, Plinkert PK, Baumann I. Development and validation of the Functional Rhinoplasty Outcome Inventory 17 (FROI-17). Rhinology. 2014; 53: 315-319.

4. Ware JE, Sherbourne CD. The MOS 36-Item Short-Form Health Survey (SF-36). I.
Conceptual frameworkand item selection. Med Care 1992; 30: 473-483

5. Bullinger M, Kirchberger I. SF-36 Fragebogen zum Gesundheitszustand. Handanweisung. 1. Auflage, HogrefeVerlagfürPsychologieGöttingen, Bern, Toronto, Seattle. 1998.

6. Most SP, Alsarraf R, Larrabee WF. Outcomes 
of facial cosmetic procedures. Facial Plast Surg. 2002;18: 119-124.

7. Faidiga GB, Carenzi LR, Yassuda CC, Silveira F, Lago Td, Leite MG, Anselmo-Lima WT. Long-term evaluation in aesthetic rhinoplasty in an academic referral center. Braz Otorhinolaryngol. 2010;76:437-441.

8. Hellings PW, NolstTrenite GJ. Long-term patient satisfaction after revision rhinoplasty. Laryngoscope. 2007; 117: 985-989.

9. Meningaud JP, Lantieri L, Bertrand JC Rhinoplasty: An outcome research. Plast. Reconstr. Surg. 2008; 121: 251-257.

10. Saleh AM, Younes A, Friedman O. Cosmetics and function: quality-of-life changes after rhinoplasty surgery. Laryngoscope. 2012 122: 254-259

11. Picavet VA, Gabriëls L, Grietens J, Jorissen
M, Prokopakis EP, Hellings PW. Preoperative symptoms of body dysmorphic disorder determine postoperative satisfaction and quality of life in esthetic rhinoplasty. Plast. Reconstr. Surg. 2013; 131: 861-868.

12. Hens G, Picavet VA, Poorten VV, Schoenaers J, Jorissen M, Hellings PW. High patient satisfaction after secondary rhinoplasty in cleft lip patients. Int Forum Allergy Rhinol. 2011; 1: 167-172

13. Neaman KC, Boettcher AK, Do VH, Mulder C, Baca M, Renucci JD, Vanderwoude DL. Cosmetic rhinoplasty: revision rates revisited. Aesthet Surg J. 2013; 33: 31-37.

14. Klassen A, Jenkinson C, Fitzpatrick R, Goddacre T. Patients' health related quality of life before and after aesthetic surgery. $\mathrm{Br}$ J Plast Surg. 1996; 49: 433-438.
O.C. Bulut, MD

Department of Otolaryngology

Im Neuenheimer Feld 400

D-69120 Heidelberg

Germany

Tel: +49(0)6221-566705

Fax: $+49(0) 6221-5633967$

E-mail:cem.bulut@med.uni-heidelberg.de 